\title{
Chinese Neologisms in the Field of Fandom: From a Rhetorical Perspective
}

\author{
Aiqing Wang \\ Lancaster University, $U K$ \\ aiqing.wang@lancaster.ac.uk
}

DOI: http://doi.org/10.36892/ijlls.v2i3.332

\begin{tabular}{ll} 
Received: & Abstract \\
19/06/2020 & In this paper I investigate Chinese neologisms in the field of fandom from a \\
& rhetorical perspective. Chinese fans either borrow existing expressions, \\
Accepted: & sometimes Internet neologisms, and employ them in a novel approach, or \\
01/09/2020 & create new expressions. Fandom neologisms may involve conceptual \\
& metaphor and conceptual metonymy. Metaphor can be categorised into \\
\hline Keywords: & playful metaphors and visual metaphors, the former of which may be \\
Chinese neologism; & concerning war, food or sex. Sex-related metaphors in fan neologisms are \\
Fandom; & expressed via euphemism by means of alphabetic words, homophones and \\
Metaphor; & altered characters, owing to social taboo and Internet language usage \\
Metonymy & regulation. In terms of fandom neologisms involving metonymy, they may be \\
& accompanied by nominalisation, verbification and hyperbole. Moreover, my \\
& observation indicates that Chinese fandom neologisms normally demonstrate \\
& semantic opaqueness, which I presume might be correlated with recognition \\
& memory. As a subcategory of Internet neologisms generated from networked \\
& grassroots communication, fandom neologisms demonstrate an upward \\
& transmission direction, as well as a potential to enter the mainstream lexicon \\
& by means of being cited by the traditional media.
\end{tabular}

\section{INTRODUCTION}

Neologisms, defined as newly coined words/expressions or the coining/use of them, flood social media in PRC and play a robust role online in the Chinese lexicon. Chinese Internet neologisms demonstrate distinctive properties. First, the innovation is realised through the creativity of Chinese netizens as grassroots language users, rather than being initiated by intellectual elites or ideological authorities. Second, the direction of transmission is horizontal in networked grassroots communication, opposite from the traditional top-down fashion, and some items even ultimately spread upwards by means of entering mainstream media. Third, digital lexical innovations reflect social realities and existential conditions of ordinary individuals, instead of the cultural, ideological and political priorities of previous neologisms with the top-down provenance (Castells 2009, 2012, Crystal 2011, Lai and Ng 2014, Tao 2017, Jing-Schmidt and Hsign 2019).

Weibo, a micro-blogging platform, was launched by a leading technology company, Sina Corporation, in 2009. The developmental stages of Weibo in PRC are characterised by its multifaceted functions, viz. collective witness, ideological arena and interest-based networks. Although being frequently referred to as the 'Chinese Twitter", Weibo does not merely imitate the established micro-blogging prototype, in that it also, more significantly, makes an unparalleled contribution to the societal landscape and public life in PRC, and plays an indispensable role in creating a vibrant space for the discursive formation of various social issues. Weibo is regarded as a social network, an event-oriented platform, a strategic tool for empowerment of grassroots advocacy, as well as a mediator facilitating the symbolic 
reconfiguration and constant construction/reconstruction of public life (Huang and Sun 2014, Poell et al 2014, Han and Wang 2015, Liu 2015, Han 2016, 2019).

As one of the most popular social media platforms in PRC, Weibo attracts a considerable amount of users: according to Statista, the number of monthly active users of Weibo amounts to approximately 550 million during the first quarter in 2020. The fundamental features of Weibo, e.g. spreadability and persistence, enable messages to reach a wide range of users and non-users.

In Mainland China, discussions of fandom, or 'fan circles', predominantly take place on Weibo. Home and international celebrities are invited to register accounts with Weibo, which attracts an enormous number of fanbases to follow their idols. Whenever a fan starts a 'topic' and is joined by other fans, the topic can potentially become a 'hot topic' and be recommended on Weibo. Driven by the contemporary rankings-focused fandom culture, fan circle members, mostly girls, spend money and volunteer time and expertise to swing public discourse and drive social media traffic, so as to make their idols as popular and influential as possible. Due to the large quantity of fans, conspicuous entertainment topics related to their idols are listed in an overwhelming way every day, causing antagonism among non-fans and anti-fans (Boyd 2010, Chen 2017, Han and Jia 2019, Ju 2019).

Among fandom discussions on Weibo, there emerges a large and ever-growing body of neologisms, in both posts and comments. Some neologisms are even incomprehensible to other young Chinese netizens if they are not members of 'fan circles', because the formation of fandom neologisms often entails morphological processes, e.g. compounding (俊白甜 shabaitian 'silly-fair-sweet', which means being naïve or refers to young females of such an attribute), abbreviation (安像鸡 an xiang ji, short for 安静得像鸡 anjing de xiang ji 'silent as a chicken', which describes low-key fans), derivation (浏览狗 liulan gou 'browsing dog', which denotes fans who only browse idol-related news and posts, but do not contribute to fandom traffic), homophony (空瓶 kongping 'empty bottle', which is a homophone of 控评 kongping 'to control comments') and loanword adaptation (糊 $h u$ 'to become a has-been', which is a phonetic loan from the English verb 'to flop').

In this article I explore neologisms related to fan circles in Mainland China from a rhetorical perspective, focusing on conceptual metaphor and conceptual metonymy. All examples are drawn from fandom comments and discussions on Weibo. In Section 2 I present theories on conceptual metaphor and conceptual metonymy. In section 3 I discuss playful metaphors related to war, food and sex, as well as visual metaphors. In Section 4 and 5 I discuss metonymy and semantic (non-)transparency respectively. Section 6 is a brief conclusion.

\section{LITERATURE REVIEW}

The theory of conceptual metaphor, associated with cognitive semantics, suggests that metaphor is conceptual in nature. Regarded as a general cognitive process of understanding one conceptual domain in terms of another, metaphor is a conceptual mapping between a more concrete 'source domain' frame and a conceptual 'target domain' frame it aims to build, so as to communicate ideas via language. Although metaphor is linguistic, gestural and visual, it is predominantly conceptual. The generalisation covering linguistic metaphors is not in language, but rather in the metaphorical concept of communication, so metaphorical thought and understanding are independent of language. Abstract everyday reason uses embodied metaphorical thought, and important abstract concepts such as Event, Action, Causation, the Mind, the Self, Morality and Being are comprehended and defined by means of multiple conceptual metaphors offering various understandings of the concepts, rather than one single conceptual metaphor. Creative and novel metaphors may entail multi-directional mapping and more than one input domain, and thus are correlated with online meaning constructions and multiple input domain integration. Additionally, a concept of conceptual 
metaphor system is proposed to characterise a domain of thought which is featured by a hierarchically structured frame as a mental structure organising knowledge (Reddy 1979, Lakoff and Johnson 1980, 1999, Fauconnier and Turner 2002, Coulson 2005, Semino 2006, 2008, 2010, Crystal 2008, Lakoff 2014).

Metonymy is a ubiquitous feature of language which informs grammar and discourse, and it plays a crucial role in shaping people's thinking about the world as well as the emergence and maintenance of cultural categories. Semiotically, metonymy is embedded in language with representational significance, because the word form represents the cognitive concept it denotes (Panther and Radden 1999, Radden and Kövecses 1999, Al-Sharafi 2004, Bierwiaczonek 2013, Dancygier and Sweetser 2014). As a cognitive process, metonymy is visualised in terms of a correspondence or mapping between entities within a conceptual domain revealed by experiential knowledge, which means one conceptual entity provides mental access to another. As for the metonymic mapping, it is structured by an idealised cognitive model defining how knowledge is organised in connection with the cultural, linguistic and natural worlds, and the mapping is realised via a linkage through pragmatic function where the source domain mentally activates the target domain. Consequently, metonymy has a conceptual effect that it experientially entails one (sub)domain to be foregrounded or highlighted by another in the matrix, and conceptual metonymy forms natural inference that are employed by participants in linguistic communication in order to derive utterance meaning (Lakoff 1987, Radden and Kövecses 1999, Croft 2002, Panther and Thornburg 2003, Barcelona 2007, 2011, Kövecses 2010, Martin and Papadelos 2017).

\section{CONCEPTUAL METAPHOR}

In this section, I discuss Chinese neologisms in the fandom field that are correlated to conceptual metaphors. These neologisms can be divided into those involving playful metaphors and those involving visual metaphors.

\section{Playful Metaphors}

Playful metaphors can be divided into two categories. One type is referred to as metaphor play or empty metaphor, which plays with sounds, but are empty of semantic content. This type of playful metaphors is of playful qualities at both formal and semantic levels, and the fun is generated by apparent playful absurdity. The other type of playful metaphors involves playful creation of metaphors, and the playfully irony is produced by counter-normative unexpectedness (Ritchie and Dyhouse 2008).

Both categories of playful metaphors can be found in Chinese neologisms among fan circles, and the playful metaphors conveyed by fandom neologism may be related to war, food and sex.

War metaphor pervades human activity, enabling readers to comprehend abstract entities through direct knowledge of war (Hu and $\mathrm{Xu}$ 2017). Han (2011) propounds that in Chinese online entertainment news, war and martial arts metaphors are playfully trivialised into martial arts fiction and computer games, which echoes Chinese and English history and literature. These playful metaphors concerning wars and martial arts correlate with cultural imagination and create a sensational and stirring fantasy, and hence increase the entertainment value of news.

In fan circles in Mainland China, war metaphorical expressions are constantly coined and widely used. The most archetypical paradigm is the title for fanatical zealots, i.e. 战斗粉 zhandou fen 'battle fan'. This neologism is constituted of 战斗 zhandou '(to) battle' and 粉 fen 'fan': the former is to describe the zeal and aggression, and the latter is a transliteration of the English word 'fan'. 'Battle fans' construe themselves as cyber warriors ready to participate in combats defending their idols, yet in the eyes of non-fans, they frequently engage in 撕逼 sibi 'catfight; trolling' and 'diss' rival fans (i.e. 安替 anti transliterated from 
the English word 'anti') or even innocent 吃瓜群众 chigua qunzhong 'melon-eating masses' (='onlookers').

To further illuminate war metaphors, I invoke a character 狙 $j u$ and its derived expressions. The verbal function of $j u$ is 'to be on the watch', and the most commonly attested compounds containing ju are 狙击 juji 'to snipe' and 狙击手 jujishou 'sniper'. When used in fandom, this verb loses its original meaning and adopts the meaning of juji 'to snipe' in a sense of 'to criticise; to attack', and common expressions on Weibo include 狙人 ju ren 'to criticise/attack someone' and 被狙 bei ju 'to be criticised/attacked'. Apart from human objects, $j u$ can also select non-human objects and form verb phrases such as 狙代言 $j u$ daiyan 'to snipe endorsement', which means to boycott products endorsed by certain celebrities, usually initiated by rival fans (对家粉 duijia fen).

Another salient example is 弹射伤害 tanshe shanghai 'ejection harm', which is derived from a military aviation terminology 弹射损伤 tanshe sunshang 'ejection injury' and is initially borrowed and altered by online game players. After being adopted by fandom members, this expression indicates harm brought to innocent fans and Internet bystanders.

It is noteworthy that war metaphors concerning fandom on Weibo are more aggressive yet less implicit than their counterparts used in traditional media. According to Han (2011), Chinese entertainment news are believed to focus on competition for supremacy, rather than fight for survival, so in playful war metaphors appearing in entertainment news, the representation of conflict in terms of war is bloodless, without any sense of death or destruction.

Mild war metaphors among fan circles on Weibo are occasionally cited by traditional media, including television and print media and their online versions. In 2019, Hong Kong protectors aroused the ire of fan girls of different celebrities in Mainland China, so the latter personified the country as their common idol and flooded social media platforms, including Twitter, Facebook and Instagram, with comments and threads supporting Hong Kong police and defending the 'One China' policy. When reporting and praising these fan girls, traditional media referred to their fandom expressions concerning wars. For instance, a government organisation, the Communist Youth League of China, launched a trending hashtag \#饭圈出 征\# fanquan chuzheng 'fan circles' military expedition' on Weibo via its verified account; 出 征 chuzheng 'military expedition' and 大军 dajun 'large army' were also used by People's Daily, an official newspaper of the Central Committee of the Communist Party of China, a provincial-level newspaper Qianjiang Evening News, Hubei Provincial Television, etc. Moreover, traditional media also cited fandom neologisms that are not related to wars but of vigorous strength, such as 力挺 liting 'to greatly support' by China Central Television and 打 call da call 'to support' by Southern Metropolis Daily.

The fact that traditional media adopt fandom neologisms is an exemplification of the upward transmission of Internet neologisms opposite from that of earlier ones. In pre- and early modern China, the spread of lexical innovation and creation was in a top-down manner initiated by elites, by means of language contact, religious teaching, as well as institutional means like mass education and political propaganda, which is disparate from Internet neologisms that are of grassroots provenances. Nevertheless, Internet neologisms may alternatively spread upwards and enter mainstream media, exhibiting a down-top transmission direction (Dai 1996, Chen 1999, Jing-Schmidt and Hsign 2019, Shi et al 2019). Examples of Chinese fandom neologisms being accepted by traditional media and government institutions in the age of citizen journalism justify the proposal that Internet neologisms may transmit upwards. 
According to Han (2011), Chinese online entertainment news often employs playful metaphors concerning food: the language play happens at the lexical level and results in a formation of a FANS ARE FOOD ITEMS metaphor at the conceptual level. Food metaphors transfer fans' affection for their idols into news writing, thereby establishing an emotional bond with readers.

A typical paradigm of Chinese neologisms in fandom is the transliteration of 'fan' into 粉(丝) fen(si) 'rice noodles' or 饭 fan 'food; rice'. The disyllabic transliteration fensi is usually used independently, yet it occasionally appears in noun phrases like 粉丝团 fensi tuan 'fan group' and 粉丝经济 fensi jingji 'fan economy'. By contrast, monosyllabic fen and fan occur in combination with other elements to form phrases: 1) N-N, e.g. 饭圈 fan quan 'fan circle' and 私生饭 sisheng fan 'privacy fan' (=stan); 2) Adj-N, e.g. 脑残粉 naocan fen 'insane fan' and 职粉 zhi fen 'professional fan'; 3) V-N, e.g. 遛粉 liu fen 'to walk fans (like dogs)' which means 'to deceive fans'. Interestingly, fen can also be employed flexibly as a transitive verb 'to be a fan of; to idolise' or an intransitive verb 脱粉 tuo fen 'to stop idolising'.

Apart from the transliterating of 'fan', the most common fandom neologism category is nicknames fans label themselves, based on the names of their idols. Fanbases' nicknames are normally names of real-world objects, the vast majority of which are food items. For example, 汤圆 tangyuan 'sticky rice dumpling' is the nickname of a fanbase whose idol's given name is Yuan, and 汉堡 hanbao 'burger' is the nickname of a fanbase whose idol's given name is Han; as can be seen, these nicknames/food names always contain a morpheme that is the homonym of the celebrity's given name. Interestingly, the word 'idol' itself is also transliterated into an expression related to food, i.e. 爱豆 aidou 'love bean'.

Metaphorically, fans compare celebrities' resources to 饼 bing 'cake; pie', namely, endorsement, acting, entertainment, etc. that feed income and fame to celebrities. The metaphor bing consequently brings about the coining and use of other related metaphors. Coined expressions include 毒饼 dubing 'poisonous cake' that portrays mediocre or even poor resources, as well as its exaggerated version 惊天大毒饼 jingtian da dubing 'stunningly big poisonous cake'. In addition to coining new words and expressions, fans also employ existing words and expressions related to bing in a novel manner. For instance, 画饼 huabing 'to draw cake' is part of an idiom 画饼充饥 huabing chongji 'to draw cake to allay hunger' ('to fantasise'), whereas in fandom it denotes the act of fans daydreaming about their idols receiving some high-quality bing, or that of media and entertainment agencies hyping some bing to give fans false hope.

Another prevalent food-related metaphor concerns 糖 tang 'sugar' that describes the sweetness of romance or interaction between real or imaged celebrity couples (abbreviated and known as ' $\mathrm{CP}$ ' in fandom). Analogous to bing, tang also generates a range of related expressions. For instance, when the sweetness is mixed with heartbreak, especially in homosexual relationships, fans would refer to the situation as 糖里有刀/玻璃渣 tang li you dao/bolizha 'there is knife/broken bits of glass in the sugar'; when a celebrity 'CP' openly shows their sweetness in public or on social media, it is called 撒/发糖 'to sprinkle/distribute sugar'. Furthermore, there is a verb phrase 嗑糖 ketang 'to eat sugar' which means 'to enjoy sweetness'. If a celebrity ' $\mathrm{CP}$ ' is overhyped or for a publicity stunt, fans would describe the tang using 难磕 nanke 'hard to eat' or its teasing homophone 男科 nanke 'andrology'.

There are other examples of food metaphors. For instance, 瓜 gua 'melon' is used to compare gossip and rumors. Consequently, to pay attention to celebrities' dirt and affairs is called 吃瓜 chigua 'to eat melon' and those who do so are called 吃瓜群众 chigua qunzhong 'melon-eating masses' (Note that chigua qunzhong may alternatively adopt a neutral meaning of 'onlookers'). Another food metaphor, 生肉 shengrou 'raw meat', is only used by 
fanbases of Western or Japanese/Korean celebrities to denote videos without translated subtitles, and its antonym 熟肉 shurou 'cooked meat' denotes videos with Chinese subtitles that are usually translated by fansubs (short for fan-subtitled).

Metaphors correlated with sex can also be found in Chinese fandom neologisms, and they usually occur in conjunction with euphemism owing to social taboo and Internet language usage regulation.

Cross-linguistically and cross-culturally, circumlocutionary expressions are employed to substitute those that are perceived as being offensive or unpleasant. The subject of sex acts as the most fertile breeding ground for euphemistic substitutes, as sex is pervasive in human life and hence is prone to trigger embarrassment. Sex-related euphemisms are constituted of sexual behaviours, associated body parts, as well as clothing in direct contact with these body parts (Rawson 1981, Andersson and Trudgill 1990, Allan and Burridge 1991, Nash 1995, Linfoot-Ham 2005, Allan and Burridge 2006, Sze 2017).

Sex-related metaphors can be accounted for in terms of Conceptual Metaphor Theory, and a cognitively motivated theory of sexual mitigation and offence can capture traits of sexrelated conceptualisation. First, the degree of lexicalisation of metaphorical substitutes affects conceptual categorisation and explains a bidirectional metaphorical projection between target and source domains. Second, nature and connotations of the source domain contribute to verbal mitigation offence in metaphorical substitutes. Third, the type of conceptualisation is crucial to the interpretation of metaphorical substitutes. Fourth, the use of cognitive metaphors in conceptually consistent contexts plays a salient role in the process of disambiguating metaphorical language (Fernández 2008).

Apart from avoiding explicitly mentioning sex as a social taboo, the fact that sex metaphors are expressed via euphemism is also because of the Internet language usage restriction in PRC. Prurient and salacious expressions might be classified as being 'sensitive' and be censored online. According to Cheng (2018), Internet language is usually employed to show users' special personality, so it tends to be emotional, imprecise and irrational. Owing to its robust transmissibility, non-standard and indecent Internet language is believed to be detrimental to the security of language, culture and ideology. In PRC, the policy of Harmonious Society (和谐社会 hexie shehui) and language policy at state and institutional levels aim for the ideal of harmony and social cohesion by means of emphasising normativity and order, yet actual developmental processes of online harmonisation are detailed, multidirectional and unpredictable (Wang et al 2016). In December 2019, Cyberspace Administration of China issued Provisions on Ecological Governance of Network Information Content that came into force since March 2020. These provisions state that Internet users shall take measures to prevent and resist the production, reproduction and publication of undesirable information containing sexual innuendo and sexual provocation; additionally, Internet users shall not make, copy or publish any illegal information disseminating obscenity or pornography (Provisions on Ecological Governance of Network Information Content 2020).

When resorting to euphemism, Chinese-speaking fans may use alphabetic words, homophones or altered characters.

The first strategy fans adopt in neologisms concerning sex metaphors is to use alphabetic words. Alphabetic words denote fully or partially romanised Chinese words. Chinese alphabetic words may contain whole foreign morphemes, e.g. hold 住 hold-zhu 'hang in there' derived from code-switching, and sometimes alphabetic words may undergo folk-etymological reinterpretation of the original foreign expressions and be used in a different way, e.g. PK 'to compete' originated from a football terminology 'penalty kick'. The other form of Chinese alphabetic words is acronyms of Pinyin (the official romanisation system for Chinese adopted in Mainland China). For instance, $l g$ stands for 老公 laogong 'hubby' (Su and Wu 2013, Hou and Teng 2016, Ding et al 2017, Huang and Liu 2017, JingSchmidt and Hsign 2019). 
Chinese fandom neologisms involving sex metaphors are predominantly acronyms of Pinyin. For instance, $b p$ stands for 白嫖 baipiao 'to solicit prostitutes for free' which describes the act of not spending money on idols' concerts, films, endorsed products, etc; $s j$ is for 视奸 shijian 'to eye-rape' which, in fan circles, means to stalk celebrities or fanbases on social media. These expressions have already existed, but they are adopted by fans in an innovative way. It is worth mentioning that in Chinese, a sexually vulgar infix-like word, which is a slang expression for the male reproductive organ, can be inserted into phrases for emphasis. Some fandom neologisms contain this infix-like noun, but due to its offensiveness, it is normally written as an acronym of Pinyin, $j b$. For instance, as mentioned previously, 嗑 $k e$ in the metaphorical expression 嗑糖 ketang 'to eat sugar' means 'to enjoy' (sweetness of romance/interaction), so the $\mathrm{Adv}-\mathrm{V}$ construction 瞎嗑 xia ke 'to blindly eat' describes the behaviour of irrationally fantasising CP's romance/interaction. In xia ke, the adverb xia and the verb $k e$ can be separated by $j b$, forming 瞎 $j b$ 嗑 xia jiba ke 'to blindly-f**king-eat' to emphasise the delusiveness.

Alternatively, sex metaphors may be alphabetic words containing foreign morphemes derived from code-switching. In an expression that has been mentioned earlier, 撕逼 sibi 'catfight; trolling', the second character is actually an euphemistic substitute of its homophone $b i$ that is a slang expression for the female reproductive organ (and the first character literally means 'to tear', so the whole phrase literally means 'to tear pussies'). To further strengthen the euphemistic effect, fans sometimes substitute $b i$ with the English letter $\mathrm{b}$ that is of the same pronunciation, generating 撕 $b$.

Second, resorting to homophones is also an approach adopted by fans when creating neologisms involving sex metaphors. Two archetypical examples are \#人设 cao renshe 'to $\mathrm{f}^{* *} \mathrm{k}$ character set' and \#热度 cao redu 'to $\mathrm{f}^{* *} \mathrm{k}$ heat' which means to irrationally construct public personas and increase popularity respectively. \# cao in this expression can be either a character indicating grass or a radical for characters related to grass, and as an Internet neologism, it is interchangeable with its homophone cao 'to $\mathrm{f}^{* *} \mathrm{k}$ '. In the fandom expression cao renshe, the verb is used in a metaphor way, comparing the act of forcing fans and nonfans to accept one's public persona to sexual intercourse. However, the verb itself is too offensive for fan girls and/or it might be blocked online as a sensitive character, so its homophone is borrowed.

The third strategy used in neologisms involving sex metaphors is to alter characters by means of separating one character into two. For example, the character 欲 $y u$ can be used as a noun indicating desire in general or specifically sexual desire. For the purpose of euphemism, fans separate this left-right-structure character into half and type two independent characters 谷欠 which are used as a single adjective to describe celebrities' sexually arousing bodies or dances. Since these two characters are merely employed to represent the image of the original character, the combination of their pronunciations or meanings does not make any sense.

\section{Visual Metaphors}

There is a special class of idioms that are both imageable and metaphorical: expressions constituting idioms activate conventional mental images with associated common knowledge. In other words, conceptual metaphor mapping applies to knowledge about images, generating meaning of idioms. Moreover, the system of metaphors in people's mind functions naturally, automatically, quickly and unconsciously, linking knowledge of images to meaning of idioms (Lakoff 1987, 2014).

As conceptual mapping, metaphor can be realised both linguistically and through other communication modes including visual images. Visual metaphor is identified in the filed of multimodal metaphor and is categorised into contextual metaphor, hybrid metaphor and simile. Contextual metaphor, in particular, denotes the comparison of a visually depicted 
object to another based on the visual context (Forceville 1996, El Refaie 2003, Goatly 2007, Feng and O'Halloran 2013, Feng 2019).

Among fandom neologisms, there is a range of visual metaphors that evoke imagery by means of comparing one object/act to another due to their visual resemblance.

Fan circles are constantly flooded with newly-invented expressions, and those concerning visual metaphors combine a fecundity of imagination and a richness of innovative humor/sarcasm. A representative paradigm is a verb 抠脚 koujiao 'to scratch one's own feet', describing a celebrity who has no or few opportunities for public exposure. A person who stays at home scratching their feet is perceived to be bored and jobless, so the image is vividly used by fans to ridicule rival fanbases' idols who are of low profile or limited resources in a sarcastic way. Another neologism related to feet is 洗脚婢 xijiao bi 'feetwashing maid' which is to denote boy or girl band members of lower popularity than others. A maid squatting down to wash others' feet is construed to be pathetic and humble, so fans create this visual metaphor to depict the low status of less popular boy/girl band members, often in a sarcastic or even insulting way. Other imagery-evoking examples include 划水 huashui 'to paddle water' which means 'to perform perfunctorily' and 拉踩 lacai 'to drag and stamp with feet' which means 'to anathematise (other celebrities one dislikes)'.

Apart from coining new words and expressions involving visual metaphors, fans also use available fixed expressions and Internet neologisms in a novel manner.

Chinese fans' creativity can be reflected by their innovative use of existing expressions in other fields. For instance, 滑趾 huagui '(to) knee slide' originally denotes (making) a football celebration movement. In a fandom context, however, huagui functions as a verb indicating 'to apologise swiftly'. This visual metaphor successfully evokes imagery, in that going down on both knees bears resemblance to kowtow for forgiveness, and the expeditiousness of knee slides indicates the apology's promptness. Another existing phrase is 爬墙 paqiang 'to climb walls': it has a plain meaning in everyday life, yet in fan circles, it vividly depicts the act of changing idols. Similarly, 按头 antou 'to press heads' has its ordinary meaning in daily life, but in the field of fandom, it either combines with 安利 anli (see below for details) to form 按头安利 antou anli 'to force others to accept/like' or with 小 分队 xiaofendui 'little team' to describe groups of fans who wish to force their ' $\mathrm{CP}$ ' to kiss by press their heads together.

Moreover, existed Internet neologisms can be adopted by fans in a creative manner. A noun phrase 白莲花 bailian hua 'white lotus flower' is an Internet neologism, referring to people, especially young female people, who are as innocent and kind as untainted lotuses, but it is later mainly used sarcastically by netizens to refer to pretentious or hypocritical people. When fans bring this neologism into their circles, they usually employ the positive meaning of bailianhua to denote their own idols, yet the negative meaning to denote celebrities who are in competition with their own idols. It is worth mentioning that the sarcastic interpretation of bailianhua has a vulgar version, viz. 白莲婊 bailian biao 'white lotus slut'. As stated by Jing-Schmidt and Peng (2018), in the Chinese cyber lexicon, a character 婊 biao 'slut' is employed socio-morphologically as a gendered pejorative personal suffix to form derivatives such as 心机婊 xinji biao 'cunning slut' and 圣母婊 shengmu biao 'holy-mother slut'.

\section{CONCEPTUAL METONYMY}

In this section I discuss fandom neologisms involving conceptual metonymy derived from nominalisation or verbification.

Metonymy, defined as 'a referential transfer phenomenon based on spatiotemporal contiguity as conceived by the speaker between an entity and another in the (real) world' (Seto 2003: 196), is marked by the salient elaboration of part-whole relations, conceptualised 
as PART FOR WHOLE or WHOLE FOR PART. Another notable metonymy is THE QUALIFICATION FOR THE PERSON, viz. the substitution theory of metonymy (Seto 1999, Barcelona 2003, Panther and Thornburg 2007, Kövecses 2010, Martin and Papadelos 2017).

A type of fan neologisms involving metonymy uses a person's characteristic to represent the whole person, which can be assumed to be a combination of PART FOR WHOLE and THE QUALIFICATION FOR THE PERSON. For instance, 小龙虾 xiao longxia 'little lobster; crayfish' contains longxia 'lobster' which is a homophone of 狵瞎 longxia 'deaf and blind'. Under circumstances when celebrities' dirt are dug out, some fans do not (want to) believe other fans' clarification and even threaten to 脱粉 tuofen 'to stop idolising', so other loyal fans would derogatorily call them xiaolongxia, using traits of being 'deaf and blind' to refer to the whole person. A similar neologism is 小透明 xiao touming 'little transparent' that denotes low-profile fans who seldom participate in discussions and hence being 'transparent'.

The above two neologisms are examples of nominalisation where adjectives function as nouns. Apart from nominalisation, verbification is also a strategy to form fandom neologisms involving metonymy.

As a form of conversion (aka zero derivation), verbification is a productive, ongoing process, and recent verbifications in English are frequently associated with Internet technology and social media, e.g. google, tweet and blog (Pinker 2007, Burkette and Kretzschmar 2018).

Chinese fandom neologisms involving conceptual metonymy can be derived via verbification. Parallel to their counterparts involving conceptual metaphor, fandom neologisms involving metonymy can also be derived from available expressions and convey novel meanings. For instance, the character 狗 gou is a common noun 'dog', yet after being brought into fan circles, it becomes a verb 'to be a groupie'. This schema is conceptualised as WHOLE FOR PART, as it uses the whole animal to denote its behaviour waiting/following its owner. Another similar example of verbification is 安利 anli 'to hype; to promote'. Anli itself is already an Internet neologism: as the name of an American multi-level marketing company, it is recently used as a verb to depict the way salespeople promote their products. 'To anli' and 'to google' are parallel in terms of their verbifying process, whereas the former is limited in an Internet context, contrary to the latter that has entered the mainstream lexicon. When brought into fandom, anli also entails narrowing of meaning: in fan circles, anli exclusively denotes hyping idols' songs, films, entertainment shows, etc, which, in a sense, narrows down its generic meaning of promoting anything or anybody.

\section{SEMANTIC (NON-) TRANSPARENCY}

Semantic transparency denotes the relation between the meaning of a whole word and those of its constituents (Libben 1998, Libben et al 2003). For a Chinese word consisting of two characters, it is transparent if its meaning can be derived from constituent characters, e.g. tea+cup=teacup, whereas it is opaque if its meaning cannot be derived from constituent characters, e.g. sun+spring=plain (Han et al 2014).

According to my observation, Chinese fandom neologisms of semantic opaqueness are larger in number than their counterparts of semantic transparency. There is a range of fandom neologisms whose meaning cannot be understood literally based on surface structures. For example, a polysemy 流量 liuliang 'flow rate; website traffic; (mobile phone) data' is originally from the field of physics, computer science or telecommunication, but it is brought into fan circles to simply refer to celebrities' popularity. Relevant compounds can be generated on the basis of liuliang, e.g. 流量小生 liuliang xiaosheng 'popular young male 
star', 流量小花 liuliang xiaohua, 'popular young female star', 流量明星 liuliang mingxing 'popular star', etc. There is also an abbreviation 顶流 dingliu that is short for dingji liuxiang mingxing 'top star', and it has a derogatory, sarcastic homophone 顶瘤 dingliu, with the second character indicating tumors.

Another example of Chinese fandom neologisms of semantic opaqueness is 爆肝 baogan 'to have one's liver exploded' that is initially an Internet neologism meaning 'to stay up'. When used in fan circles, baogan means to stay up increasing idols' social media traffic via software and/or multiple sockpuppet accounts. The correlation between staying up and having one's liver exploded lies in that according to traditional Chinese medicine, staying up late is detrimental to human liver. Therefore, Chinese netizens coin this new word in a joking way to imply that one's liver would explode if one stays up late. It is notable that the semantic opaqueness of this neologism is partially attributed to hyperbole. Regarded as a type of metaphor, hyperbole refers to a figure of speech marked by conspicuous exaggeration; it makes impossible or comparative absolute propositions and achieves the effect by means of ostensible contradictions (Stanivukovic 2007, McFadden 2012). In baogan, the harm of staying up has been made more serious than it really is.

There are, of course, fandom neologisms whose meanings are less difficult to understand judged from their surface structures, e.g. 玻璃心 boli xin 'glass-hearted' (=oversensitive), 纯路人 chun luren 'pure passer-by' (=non-fan), 追星狗 zhuixing gou 'star-chasing dog' (=fan), 无脑吹 wunao chui 'to brainlessly extol', etc.

As for the reason why neologisms in the filed of fandom are predominantly featured by semantic opaqueness, I hypothesise that it might be attributed to recognition memory. Words with distinct characteristics, frequently employed as stimuli to research on recognition memory, can be perceived as mini-events parallel to various kinds of episodes experienced in real life (Tulving 1983). For two-character Chinese words, semantic transparency serves as a linguistic property modulating their recognition memory. To be more specific, being morphologically more complex and harder to process during lexical access, opaque words are memorised better than their transparent counterparts, as distinctiveness enhances recollective experience and phenomenology of familiarity (Libben 1998, Kishiyama and Yonelinas 2003, Libben et al 2003, Ozubko et al 2012, Han et al 2014).

\section{CONCLUSION}

Chinese neologisms in the field of fandom are either formed by means of borrowing existing expressions or Internet neologisms, or through coining new expressions. From a rhetorical perspective, Chinese fandom neologisms can be divided into those involving conceptual metaphor and those involving conceptual metonymy. Metaphors appearing in fandom neologisms are constituted of playful metaphors and visual metaphors, the former of which may be related to war, food or sex.

In order to comply with Internet language usage regulation, and to avoid explicitly addressing sex as a social taboo, when creating and employing sex metaphors, fans tend to resort to euphemism. To be more specific, fan neologisms involving sex metaphors adopt the forms of alphabetic words, homophones and altered characters.

Conceptual metonymy can also be found in Chinese fan neologisms, and it may occur together with nominalisation, verbification and hyperbole.

Chinese fan neologisms are predominantly featured by semantic opaqueness, which I assume might be correlated with recognition memory: opaque expressions of morphological complexity entail more processing efforts in lexical access, so they are memorised more effectively accordingly than their transparent counterparts.

During the era of citizen journalism, fandom neologisms in networked grassroots communication may undergo upwards transmission and enter mainstream social discourse. 
Official recognition from traditional media and government institutions illuminates the significance of fandom neologisms, so further research can be conducted in the future.

\section{REFERENCES}

Allan, K. \& Burridge, K. (1991). Euphemism and dysphemism: Language used as shield and weapon. Oxford: Oxford University Press.

Allan, K. \& Burridge, K. (2006). Forbidden words. New York: Cambridge University Press.

Al-Sharafi, Abdul Gabbar Mohammed. 2004. Textual Metonymy: A Semiotic Approach. Basingstoke: Palgrave Macmillan.

Andersson, L. \& Trudgill, P. (1990). Bad language. Oxford: Oxford University Press.

Barcelona, A. (2003). Metonymy in Cognitive Linguistics. An Analysis and a Few Modest Proposals. In Cuyckens, H. Berg, T. Dirven R. \& Panther K-U. (eds), Motivation in Language: Studies in Honor of Günter Radden. Amsterdam: John Benjamins, 223-255.

Barcelona, A. (2007). The Role of Metonymy in Meaning Construction at Discourse Level. In Radden, G. Köpcke, K.-M. Berg, T. \& Siemund, P. (eds.), Aspects of Meaning Construction, Amsterdam: John Benjamins. 51-75.

Barcelona, A. (2011). Reviewing the Properties and Prototype Structure of Metonymy. In Benczes, R. Barcelona, A. \& Ruiz de Mendoza Ibáñez, F. J. (eds), Defining Metonymy in Cognitive Linguistics: Towards a Consensus View, Amsterdam: John Benjamins. 7-57.

Bierwiaczonek, B. (2013). Metonymy in Language, Thought and Brain. Sheffield: Equinox.

Burkette, A. \&. Kretzschmar Jr W. A. (2018). Exploring Linguistic Science: Language Use, Complexity, and Interaction. Cambridge: Cambridge University Press.

Boyd, D. (2010). Social network sites as networked publics: Affordances, dynamics, and implications. In Papacharissi, Z. (ed.), Networked Self: Identity, Community, and Culture on Social Network Sites. New York, NY and Abingdon, UK: Routledge. 39-58.

Castells, M. (2009). Communication power. Oxford and New York: Oxford University Press.

Castells, M. (2012). Networks o f outrage and hope. Cambridge: Polity Press.

Chen, J. (1999). Chinese Language and Chinese Society. Guangzhou: Guangdong Jiaoyu Chubanshe.

Chen, L. (2017). Chinese Fans of Japanese and Korean Pop Culture: Nationalistic Narratives and International Fandom. Milton: Routledge.

Cheng, P. (2018). Sixiang zongheng: Jinghua wangluo yuyan. People's Daily, 6(5), 7.

Coulson, S. (2005). What's so funny? Cognitive semantics and jokes. Cognitive Psychopathology, $2(3), 67-78$.

Croft, W. (2002). The Role of Domains in the Interpretation of Metaphors and Metonymies. In Dirven, R. \& Pörings, R. (eds), Metaphor and Metonymy in Comparison and Contrast, Berlin: Mouton De Gruyter. 161-205.

Crystal, D. (2008). A Dictionary of Linguistics and Phonetics. Malden, MA: Blackwell Publishing.

Crystal, D. (2011). Internet linguistics. London and New York: Routledge.

Dai, Z. (1996). Introduction to cultural philology. Beijing: Yuwen Chubanshe.

Dancygier, B. \& Sweetser, E. (2014). Figurative Language. Cambridge: Cambridge University Press.

Ding, H., Zhang, Y, Liu, H. \& Huang, C.-R. (2017). A preliminary phonetic investigation of alphabetic words in Mandarin Chinese. Paper presented at Interspeech, Stockholm, Sweden.

El Refaie, E. (2003). Understanding Visual Metaphor: The Example of Newspaper Cartoons. Visual Communication, 2(1), 75-95.

Fauconnier, G. \& Turner, M. (2002). The Way We Think: Conceptual Blending and the Mind's Hidden Complexities. New York, NY: Basic Books.

Feng, D. (2019). Analyzing multimodal Chinese discourse: Integrating social semiotic and conceptual metaphor theories. In Shei, C. (ed.), The Routledge Handbook of Chinese Discourse Analysis, New York, NY: Routledge. 65-81.

Feng, D. \& O'Halloran. K. (2013). The Visual Representation of Metaphor: A Social Semiotic Approach. Review of Cognitive Linguistics, 11(2), 320-335.

Fernández, E. C. (2008). Sex-Related Euphemism and Dysphemism: An Analysis in Terms of Conceptual Metaphor Theory. Atlantis, 30(2), 95-110.

Forceville, C. (1996). Pictorial Metaphor in Advertising. London: Routledge.

Goatly, A. (2007). Washing the Brain - Metaphor and Hidden Ideology. Amsterdam: John Benjamins. 
Han, C. (2011). Reading Chinese online entertainment news: Metaphor and language play. Journal of Pragmatics, 43, 3473-3488.

Han, E. L. (2016). Micro-blogging Memories: Weibo and Collective Remembering in Contemporary China. Basingstoke: Palgrave Macmillan.

Han, E. L. (2019). The discourse of Chinese social media: The case of Weibo. In Shei, C. (ed.), The Routledge Handbook of Chinese Discourse Analysis, New York, NY: Routledge. 379-390.

Han, G. \& Wang, W. (2015). Mapping User Relationships for Health Information Diffusion on Microblogging in China: A Social Network Analysis of Sina Weibo. Asian Journal of Communication, 25(1), 65-83.

Han, R. \& Jia, L. (2019). Rescuing authoritarian rule: The anti-Gongzhi discourse in Chinese cyberspace. In Shei, C. (ed.), The Routledge Handbook of Chinese Discourse Analysis, New York, NY: Routledge. 415-427.

Han, Y-J. Huang, S.-C., Lee, C.-Y., Kuo, W.-J., \& Cheng, S,-K. (2014). The modulation of semantic transparency on the recognition memory for two-character Chinese words. Memory and Cognition, 42(8), 1315-1324.

Hou, M. \& Teng, Y. (2016). Six years of alphabetic words. Language Strategy Research, 3, 34-42.

$\mathrm{Hu}$, C. \& Xu, Y. (2017). WAR Metaphor in the Chinese Economic Media Discourse. Higher Education Studies, 7(1), 94-106.

Huang, C.-R. and Liu, H. (2017). Corpus-based automatic retrieval and analysis of Chinese alphabetic words. Journal of Yunnan Normal University, 49(3), 10-21.

Huang, Ronggui and Xiaoyi Sun. (2014). Weibo Network, Information Diffusion and Implications for Collective Action in China. Information, Communication and Society 17.1: 86-104.

Jing-Schmidt, Z. \& Hsieh, S.-K. (2019). Chinese Neologisms. In Huang, C. R., Jing-Schmidt, Z. \& Meisterernst, B. (eds.), Routledge Handbook of Chinese Applied Linguistics, New York, NY: Routledge. 514-534.

Jing-Schmidt, Z. \& Peng, X. (2018). The sluttified sex: Verbal misogyny reflects and reinforces gender order in wireless China. Language in Society, 47(3), 385-408.

Ju, C. (2019). How China's Star Ship Troopers Are Redefining Modern Fandom. Sixth Tone.

Kishiyama, M. M. \& Yonelinas, A. P. (2003). Novelty effects on recollection and familiarity in recognition memory. Memory and Cognition, 31(7), 1045-1051.

Kövecses, Z. (2010). Metaphor: A Practical Introduction. Oxford: Oxford University Press.

Lai, S. \& Ng, V. (2014). Collaborative discovery of Chinese neologisms in social media. 2014 IEEE International Conference on Systems, Man, and Cybernetics, 4107-4112.

Lakoff, G. (2014). Mapping the brain's metaphor circuitry: metaphorical thought in everyday reason. Frontiers in Human Neuroscience, 8, 1-14.

Lakoff, G. \& Johnson, M. (1980). Metaphors We Live By. Chicago: University of Chicago Press.

Lakoff, G. (1987). Women, Fire, and Dangerous Things. Chicago: University of Chicago Press.

Lakoff, G. \& Johnson, M. (1999). Philosophy in the Flesh: The embodied mind and its challenge to western thought. New York, NY: Basic Books.

Libben, G. (1998). Semantic transparency in the processing of compounds: Consequences for representation, processing, and impairment. Brain and Language, 61(1), 30-44.

Libben, G., Gibson, M., Yoon, Y. B. \& Sandra, D. (2003). Compound fracture: the role of semantic transparency and morphological headedness. Brain and Language, 84(1), 50-64.

Linfoot-Ham, K. (2005). The linguistics of euphemism: A diachronic study of euphemism formation. Journal of Language and Linguistics, 4(2), 227-263.

Liu, Y. (2015). Tweeting, re-tweeting, and commenting: microblogging and social movements in China. Asian Journal of Communication, 567-583.

Martin, P. \& Papadelos, P. (2017). Who stands for the norm? The place of metonymy in androcentric language. Social Semiotics, 27(1), 39-58.

McFadden, K. (2012). Hyperbole. In Greene, R., Cushman, S. \& Cavanagh, C. (eds.), Princeton Encyclopedia of Poetry and Poetics, Princeton, N.J.: Princeton University Press. 648.

Nash, W. (1995). Fair words and foul. In Svartvik, J. (ed.), Words: Proceedings of an international symposium, Kungl: Vitterhets Historie och Antikvitets Akademien. 23-38.

Ozubko, J. D. Gopie, N. \& MacLeod, C. M. (2012). Production benefits both recollection and familiarity. Memory and Cognition, 40(3), 326-338.

Panther, K.-U. \& Radden, G. (1999). Metonymy in Language and Thought. Amsterdam: John Benjamins. 
Panther, K.-U. \& Thornburg, L. (2003). Introduction: On the Nature of Conceptual Metonymy. In Panther K.-U. \& Thornburg, L. (eds.), Metonymy and Pragmatic Inferencing, Amsterdam: John Benjamins. 1-20.

Panther, K.-U. \& Thornburg, L. (2007). Metonymy. In Geeraerts D. \& Cuyckens, H. (eds.), The Oxford Handbook of Cognitive Linguistics, New York: Oxford University Press. 236-263.

Pinker, S. (2007). The Language Instinct. New York, NY: Harper Perennial Modern Classics.

Poell, T., de Kloet, J. \& Zeng, G. (2014). Will the Real Weibo Please Stand Up? Chinese Online Contention and Actor-Network Theory. Chinese Journal of Communication, 7(1), 1-18.

Provisions on Ecological Governance of Network Information Content. (2020). The Cyberspace Administration of China.

Radden, G. \& Kövecses, Z. (1999). Towards a Theory of Metonymy. In Panther K.-U. \& Radden, G. (eds.), Metonymy in Language and Thought, Amsterdam: John Benjamins. 17-59.

Rawson, H. (1981). A dictionary of euphemisms and other doubletalk. New York: Crown.

Reddy, M. J. (1979). The conduit metaphor: A case of frame conflict in our language about language. In Ortony, A. (ed.), Metaphor and Thought, Cambridge: Cambridge University Press. 164-201.

Ritchie, L. D. \& Dyhouse, V. (2008). Hair of the frog and other empty metaphors: The play element in figurative language. Metaphor and Symbol, 23, 85-107.

Semino, E. (2006). Blending and characters' mental functioning in Virginia Woolf's Lappin and Lapinova. Language and Literature, 15(1), 55-72.

Semino, E. (2008). Metaphor in Discourse. Cambridge: Cambridge University Press.

Semino, E. (2010). Unrealistic scenarios, metaphorical blends and rhetorical strategies across genres. English Text Construction, 3(2), 250-274.

Seto, K.-i. (1999). Distinguishing Metonymy from Synecdoche. In Panther K.-U. \& Radden, G. (eds.), Metonymy in Language and Thought, Amsterdam: John Benjamins. 91-120.

Seto, K.-i. (2003). Metonymic Polysemy and Its Place in Meaning Extension. In Nerlich, B. Todd, Z. Herman, V. \& Clarke, D. D. (eds.), Polysemy: Flexible Patterns of Meaning in Mind and Language, Berlin: Mouton De Gruyter. 195-214.

Shi, J., Shi, J. \& Xiong, J. (2019). Chinese language and Buddhism. In Huang, C.-R. Jing-Schmidt, Z. \& Meisterernst, B. (eds.), The Routledge handbook of Chinese applied linguistics, London: Routledge. 28-43.

Stanivukovic, G. (2007). 'Mounting Above the Truthe': On Hyperbole in English Renaissance Literature. Forum for Modern Language Studies, 43, 9-33.

$\mathrm{Su}, \mathrm{X} . \& \mathrm{Wu}, \mathrm{X}$. (2013). Vitality and limitations of alphabetic words: On the careful treatment of alphabetic words in Modem Chinese Dictionary. Journal of Beihua University, 14(2), 11-14.

Sze, F. Y. B., Wei, M. X. \& Wong, A. Y. L. (2017). Taboos and euphemisms in sex-related signs in Asian sign languages. Linguistics, 55(1), 153-205.

Tao, Y. (2017). An Investigation Into Chinese Internet Neologisms. Canadian Social Science, 13(2), 65-70.

Tulving, E. (1983). Element of episodic memory. Oxford: Oxford University Press.

Wang, X., Juffermans, K. \& Du, C. (2016). Harmony as language policy in China: An Internet perspective. Language Policy, 15, 299-321.

\section{$\underline{A U T H O R ' S B I O}$}

Aiqing Wang is a Senior Teaching Associate in Chinese Studies at the Department of Languages and Cultures, Lancaster University. She received a PhD in Linguistics and her doctoral project investigated Late Archaic Chinese syntax. Apart from syntax, her ongoing research interest also includes cultural studies. 